\title{
Superior Thyroid Artery
}

National Cancer Institute

\section{Source}

National Cancer Institute. Superior Thyroid Artery. NCI Thesaurus. Code C53021.

An artery that is the first branch of the external carotid artery that supplies the upper thyroid gland and its muscles and branches to form the crico-thyroid, hyoid, sternomastoid and superior laryngeal arteries. 